\title{
Acetylcholine-Induced Relaxation of Rat Aorta Is Greatest during Estrus in the Sexual Cycle
}

\author{
Hideo Honda, Hisayuki lshihara, Mai Takei and Hiroshi Kogo \\ Department of Pharmacology, Tokyo University of Pharmacy and Life Science, 1432-1, Horinouchi, Hachioji, Tokyo 193-03, Japan \\ Received January 29, 1997 Accepted March 7, 1997
}

\begin{abstract}
Acetylcholine (ACh)-induced relaxation in the aortae precontracted with norepinephrine was significantly enhanced in the aortae from estrus (E) rats, compared with that in those from metestrus (D-1), diestrus (D-2) and proestrus (PE) rats. $N^{G}$-Nitro-L-arginine methyl ester (L-NAME) inhibited the endothelium-dependent relaxation in $\mathrm{E}$ rats. These results suggest that there is a difference in $\mathrm{ACh}$-induced relaxation of the thoracic aorta during the sexual cycle of rats, and the relaxation is greatest in E of the sexual cycle; this may be due to a difference in nitric oxide synthesis in the endothelium in the sexual cycle.
\end{abstract}

Keywords: Sexual cycle, Nitric oxide, Aorta

Pregnancy in humans and different mammalian species, including rats, results in a decreased sensitivity to various pressor substances $(1,2)$. It is also reported that the contractility of blood vessels in response to vasoactive agents is blunted in pregnant sheep (3), guinea pigs (4) and rats $(5-7)$. Recently, we reported that the endothelium-dependent relaxation induced by acethylcholine (ACh) was significantly enhanced in aortae from pregnant rats, compared with that in aortae from nonpregnant rats (8). It is well-known that the levels of serum sexual hormones change during the sexual cycle of rats as well as during pregnancy. Therefore, the aim of the present study was to determine if there is a differnce in ACh-induced relaxation during the sexual cycle of rats.

Eight-week-old female Wistar rats in metestrus (D-1), diestrus (D-2), proestrus (PE) and estrus (E) were anesthetized by ether and sacrificed by bleeding. The thoracic aorta was isolated and placed in Hepes solution (pH 7.4) having the following composition: $120.3 \mathrm{mM}$ $\mathrm{NaCl}, 4.8 \mathrm{mM} \mathrm{KCl}, 1.8 \mathrm{mM} \mathrm{CaCl}_{2}, 1.3 \mathrm{mM} \mathrm{MgSO}_{4}, 1.2$ $\mathrm{mM} \mathrm{KH} \mathrm{PO}_{4}, 5.6 \mathrm{mM}$ glucose and $10.0 \mathrm{mM}$ Hepes $(N-2$ hydroxyethylpiperazine- $N$-2-ethanesulfonic acid) at $37^{\circ} \mathrm{C}$ gassed with $100 \% \mathrm{O}_{2}$. The $\mathrm{pH}$ was adjusted to 7.4 by adding $1.0 \mathrm{~N} \mathrm{NaOH}$. The tissue was cleaned by removing connective tissue. The throracic aorta was cut into rings about 4-mm-long. Contraction was measured by suspending the rings between two stainless-steel hooks, one of which was attached to the end of a bathing tube and the other connected to a force transducer (45196A; NEC San-ei, Tokyo). The resting tension was $0.5 \mathrm{~g}$, and each preparation was equilibrated in the $10-\mathrm{ml}$ bathing solution for 90-120 min before the experiment. Isometric tension changes were recorded on a polygraph (LECTHORIZ-8K, NEC San-ei). After the equilibration, the rings were exposed to $50 \mathrm{mM} \mathrm{KCl}$. When the contractile responses plateaued, the rings were rinsed with Hepes solution and allowed to equilibrate for an additional $60 \mathrm{~min}$ before the application of $3 \times 10^{-7} \mathrm{M}$ norepinephrine (NE). For the relaxation studies, submaximal tone (approximately $80 \%$ of the maximum tone) was induced with $3 \times 10^{-7} \mathrm{M}$ NE and then ACh or sodium nitroprusside (SNP) was added in a cumulative fashion. $N^{G}$-nitro-L-arginine methyl ester (L-NAME) was added to the solution 5 min before treatment with NE to observe the effect of L-NAME on ACh- or SNP-induced relaxation. ACh chloride, SNP and L-NAME (Sigma, St. Louis, MO, USA ) were dissolved in distilled water. Other chemicals were of analytical grade and obtained from Wako Pure Chem. Co., Ltd. (Osaka). Values were expressed or plotted as the mean \pm S.E., and statistical analysis was performed with the multiple Tukey test. Differences were considered significant at $\mathbf{P}<0.05$.

The addition of ACh $\left(10^{-8}-3 \times 10^{-5} \mathrm{M}\right)$ produced dose-dependent relaxation in the rings from D-1, D-2, PE and $\mathrm{E}$ rats (Fig. 1). ACh-induced relaxation was significantly enhanced in the thoracic aortae from $E$ rats compared with that in aortae from D-1, D-2 and PE rats. The negative logarithm of $E D_{50}$ values for efficacy (defined as percentage of relaxation per dose of agonists divided by maximum relaxation achieved in that arterial 


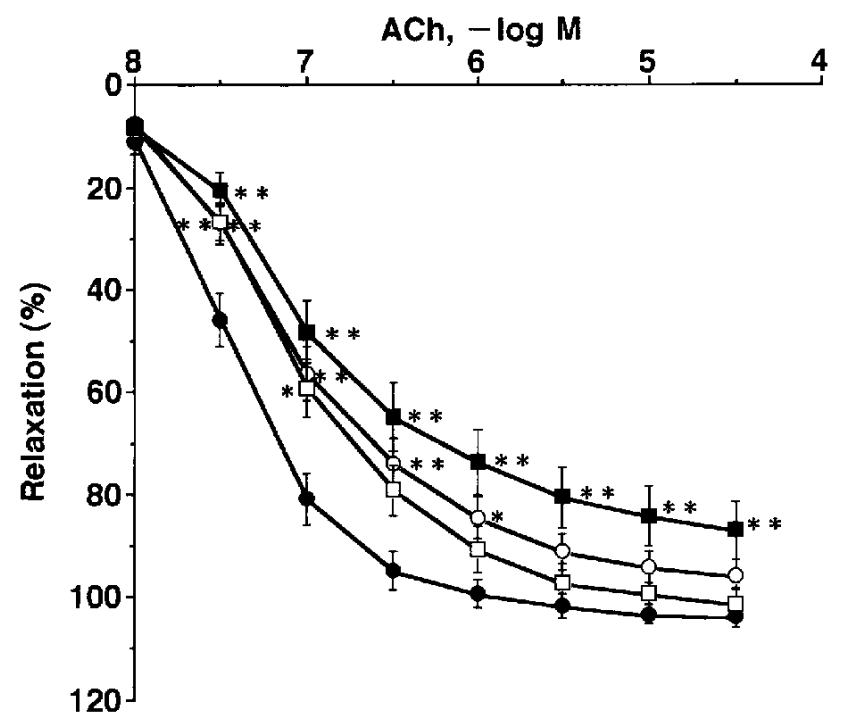

Fig. 1. Cumulative relaxation to acetylcholine (ACh) of the aortic rings precontracted with norepinephrine in fermale rats. $\square$ : D-1, metestrus; $\square$ : D-2, diestrus; $\bigcirc:$ PE, proestrus; O: E, estrus. Data are expressed as a percentage of the response to norepinephrine. Each value is the mean $=$ S.E. from $11-24$ experiments. ${ }^{*} \mathrm{P}<0.05$, $* * \mathrm{P}<0.01$ from $\mathrm{E}$.

ring) calculated from 17-24 determinations in D-1, $\mathrm{D}-2, \mathrm{PE}$ and $\mathrm{E}$ rats were $7.03 \pm 0.097,6.92 \pm 0.101$, $7.04 \pm 0.085$ and $7.37 \pm 0.073$, respectively. The negative

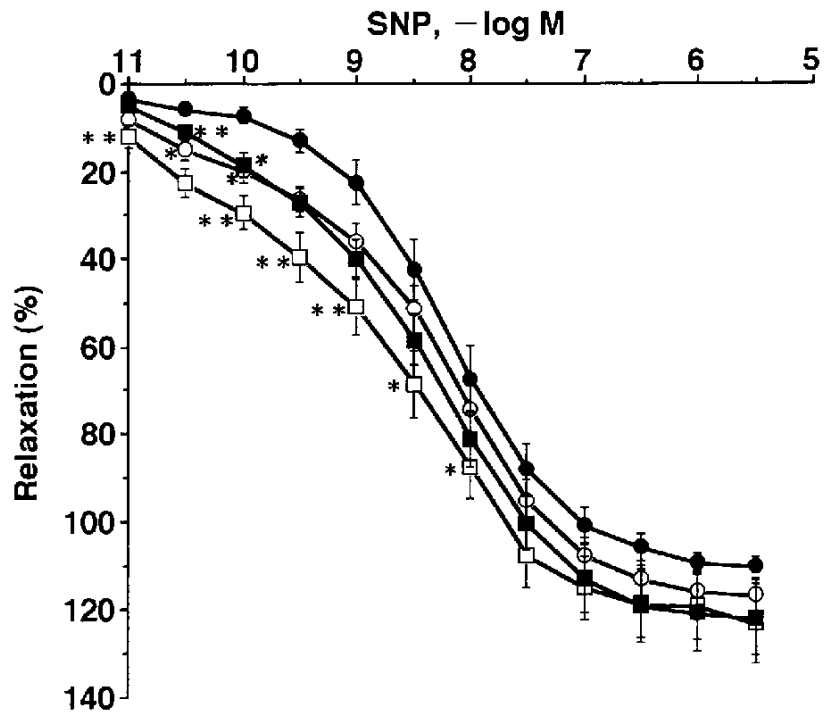

Fig. 2. Cumulative relaxation to sodium nitroprusside (SNP) of the aortic rings precontracted with norepinephrine in female rats. $\Gamma$ : D-1, metestrus; $\square$ : D-2, diestrus; $\bigcirc$ : PE, proestrus; E, estrus. Data are expressed as a percentage of the response to norepinephrine. Each value is the mean \pm S.E. from 11-24 experiments. ${ }^{*} \mathrm{P}<0.05,{ }^{* *} \mathrm{P}<0.01$ from $\mathrm{E}$.

logarithm of $\mathrm{ED}_{50}$ values for $\mathrm{ACh}$ was significantly higher in $\mathrm{E}$ rats than in D-1 $(\mathrm{P}<0.01), \mathrm{D}-2(\mathrm{P}<0.05)$ and $\mathrm{PE}$ rats $(P<0.05)$. $E$ was associated with increased efficacy of
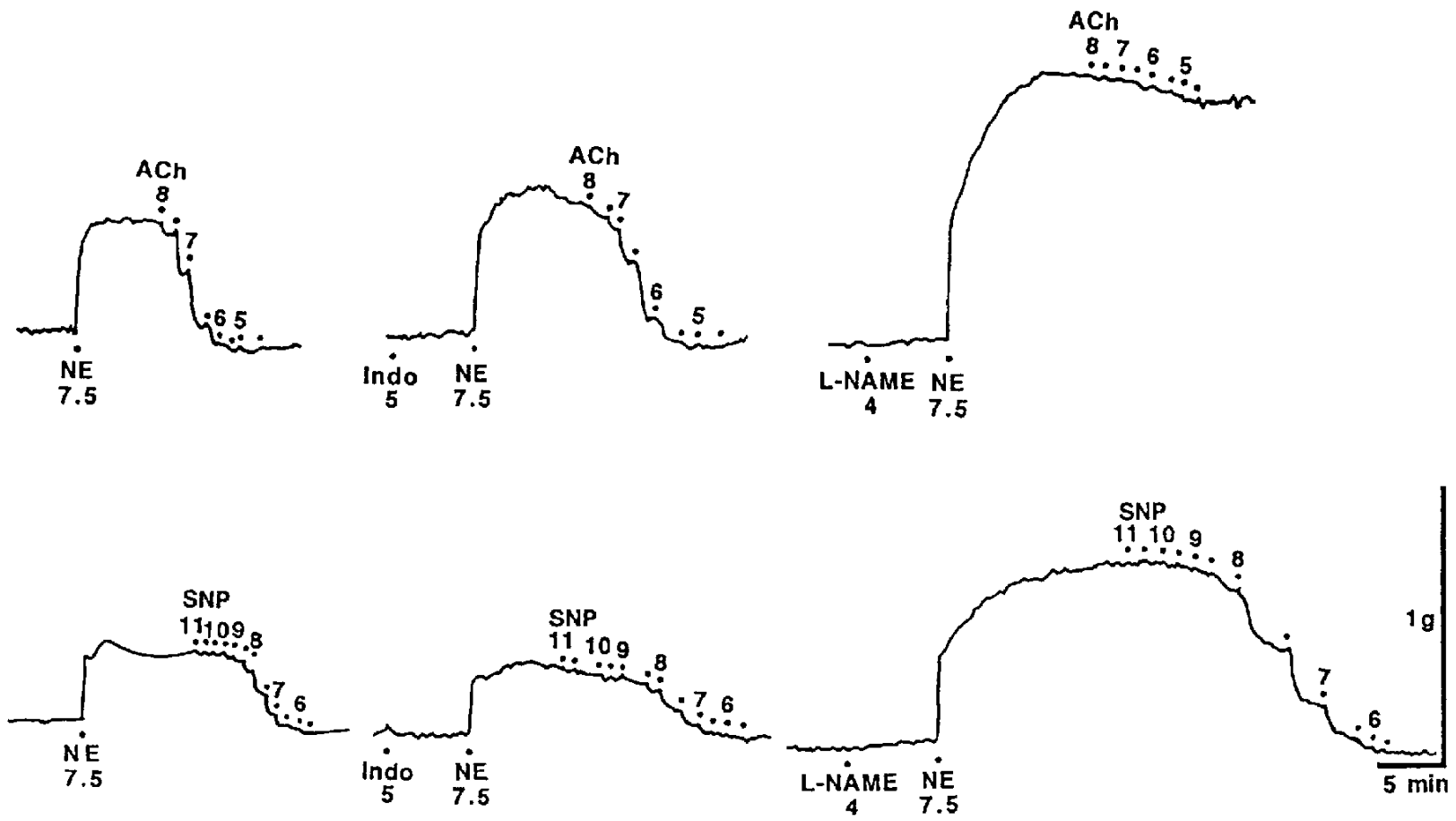

Fig. 3. Individual experimental traces of acetylcholine (ACh)- and sodium nitroprusside (SNP)-induced relaxation of aortic rings precontracted with norepinephrine (NE), and influence of indomethacin (Indo) and $N^{G}$-nitro-L-arginine metylester (L-NAME) on the relaxation in estrus rats. Figure indicates negative logarithm of drug concentration. 
$\mathrm{ACh}$ for the thoracic aorta.

In contrast to $\mathrm{ACh}$, the relaxation to cumulative SNP was decreased in $E$ rats compared with those from D-1, D-2 and PE rats (Fig. 2). The negative logarithms of $E_{50}$ values for efficacy calculated from 11-15 determinations in $\mathrm{D}-1, \mathrm{D}-2, \mathrm{PE}$ and $\mathrm{E}$ rats were $8.70 \pm 0.097$, $8.50 \pm 0.125,8.33 \pm 0.087$ and $8.22 \pm 0.137$, respectively. The negative logarithm of the $\mathrm{ED}_{50}$ value for SNP was significantly lower in $\mathrm{E}$ rats than in $\mathrm{D}-1$ rats $(\mathrm{P}<0.05)$.

The relaxation induced by $\mathrm{ACh}$ was abolished by $\mathrm{L}$ NAME $\left(10^{-4} \mathrm{M}\right)$ but did not affected by indomethacin $\left(10^{-5} \mathrm{M}\right)$ (Fig. 3). However, the relaxation induced by SNP was not affected by L-NAME $\left(10{ }^{4} \mathrm{M}\right)$ or indomethacin $\left(10^{-5} \mathrm{M}\right)$.

Our present results indicate that there was a difference in ACh-induced relaxation during the sexual cycle of rats. The relaxation induced by $\mathrm{ACh}$ was significantly enhanced in the aortae from $E$ rats, compared with those from D-1, D-2 and PE rats. There may be a possibility that the muscarinic receptors are altered, but to our knowledge, there is no report that functions of muscarinic receptors in the aortae were altered during the sexual cycle of rats. The relaxation induced by $\mathrm{ACh}$ in $\mathrm{E}$ rats was abolished by L-NAME but was not affected by indomethacin, suggesting that the enhanced relaxation by $\mathrm{ACh}$ was due to the increase of nitric oxide (NO) activity. It was reported that pregnancy enhanced the endothelium-dependent relaxation induced by $\mathrm{ACh}$ in guinea pig uterine artery (9) and rat aorta (8), suggesting that the enhancement by pregnancy was due to estradiol $(8,10)$. In these studies, non-pregnant animals were used without consideration of the sexual cycle, so it was considered that there were no great difference in the endothelium-dependent relaxation induced by ACh between non-pregnant and pregnant animals because there was a difference in $\mathrm{ACh}$-induced relaxation during the sexual cycle.

According to Watanabe et al. (11), the level of plasma estradiol in $\mathrm{PE}$, one day before $\mathrm{E}$, is the highest during the sexual cycle of rats. It is of interest that $\mathrm{ACh}$-induced relaxation is higher in $\mathrm{E}$ rats than in $\mathrm{PE}$ rats even though the level of serum estradiol is higher in PE rats than in $E$ rats. More than several hours of the high level of serum estradiol may be needed to enhance ACh-induced relaxation. Indeed, in pregnant rats, the level of serum estradiol progressively increased and reached more than tenfold on day 18, 3 days before the observation of the enhanced endothelium-dependent relaxation induced by $\mathrm{ACh}(8)$. The enhancement of $\mathrm{ACh}$-induced relaxation in both $\mathrm{E}$ and pregnant rats may be due to the increase in NO syn- thase (NOS) activity that resulted from the enzyme induction by estradiol. Weiner et al. (10) suggested that the increase in NOS activity was the result of augmented enzyme synthesis since it was accompanied by the increase in the specific mRNAs for eNOS in skeletal muscle from estradiol-treated guinea pigs. The decreased response to SNP in $\mathrm{E}$ rats may be due to the down-regulation after the increased basal release of NO.

In conclusion, there is a difference in the ACh-induced relaxation of the thoracic aorta during the rat sexual cycle, and ACh-induced relaxation is greatest in $\mathbf{E}$. It may be related to the enhancement of NO activity in the endothelium.

\section{REFERENCES}

1 Gant NF, Daley GL, Chand S, Whalley PJ and MacDonald PC: A study of angiotensin-II pressor response throughout primigravida pregnancy. J Clin Invest 52, 2682-2689 (1973)

2 Paller MS: Decreased pressor responsiveness in pregnancy: Studies in experimental animals. Am J Kidney Dis 9, 308-311 (1987)

3 Magness RR and Rosenfeld CR: Mechanism of altered pressor responses to alpha agonists in ovine pregnancy. Am J Obstet Gynecol 159, 252-261 (1988)

4 Weiner CP, Thompson LP, Liu KZ and Herrig JE: Pregnancy reduces serotonin-induced contraction of guinea pig uterine and carotid arteries. Am J Physiol 263, H1764-H1769 (1992)

5 Fuch KL, Grindlay-Moore L and Rounds S: Pulumonary vascular reactivity is blunted in pregnant rats. Eur J Pharmacol 25, 267-269 (1982)

6 Massicotte GS, Louis J, Parant A and Schiffrin EL: Decreased in vitro responses to vasoconstrictors during pregnancy in normotensive and spontaneously hypertensive rats. Can J Physiol Pharmacol 65, 2466-2471 (1987)

7 Aloamaka CP, Ezimokhai $\mathrm{M}$ and Morrison J: The role of endothelium in phenylephrine- and potassium-induced contractions of the rat aorta during pregnancy. Res Exp Med 193, 407-417 (1993)

8 Honda H, Kaneko H, Kondo $M$ and Kogo $H$ : Comparison of endothelium-derived relaxing factor activity between nonpregnant and pregnant rats. Comp Biochem Physiol 114C, 193-196 (1996)

9 Weiner CP, Martinez E, Chestnut DH and Ghodsi A: In vitro release of endothelium-derived relaxing factor by acetylcholine is increased during the guinea pig pregnancy. Am J Obstet Gynecol 161, 1605-1610 (1989)

10 Weiner CP, Lizasoain I, Baylis SA, Knowles RG, Charles IG and Moncada S: Induction of calcium-dependent nitric oxide synthases by sex hormones Proc Natl Acad Sci USA 91, $5212-5216$ (1994)

11 Watanabe G, Taya $\mathrm{K}$ and Sasamoto S: Dynamics of ovarian inhibin secretion during the oestrous cycle of the rat. $J$ Endocrinol 126, $151-157$ (1990) 